\title{
Sanguinarine and Chelidonine Synergistically Induce Endosomal Toll-like Receptor and M1-Associated Mediators Expression
}

\author{
Nuchsupha Sunthamala* (D), Chutimun Suebsamran (D), Niramon Khruaphet ${ }^{(D)}$, \\ Neeranuch Sankla (D), Janchai Janpirom (D), Surasak Khankhum* (D), \\ Rungruedee Thiwthong $(\mathbb{D}$ and Sununta Chuncher
}

Department of Biology, Faculty of Science, Mahasarakham University, Mahasarakham, 44150, Thailand.

\begin{abstract}
Natural compounds represent the great capability to stimulate several cell types. Macrophage plays an important role for an effective immune response for infection and inflammation. Isoquinoline alkaloid, sanguinarine, and chelidonine are active compounds that exhibit activity on various tumor cells and immune cells. However, the effect of these compounds on the endosomal toll-like receptor (enTLR) and type I interferon (IFN) are still unclear. The monocyte-derived macrophages (MDMs) were cultured and were determined their cell viability and phagocytic activity to Staphylococcus aureus DMST8840. The nitric oxide (NO) production and inducible nitric oxide synthase (iNOS) expression were also examined. The expression of enTLRs, type I IFN, and cytokines were determined by real-time PCR. Result shows that the compounds did not affect on MDM cell viability. Sanguinarine and chelidonine enhance phagocytic activity of MDM against Staphylococcus aureus DMST8840 by revealing a higher number of bacterial survival than the MDM treated by polyl:C, and the cell control after co-culture for 3 $h$. The production of NO has no difference amount but iNOS mRNA production was down-regulated in sanguinarine, chelidonine and their mixed treated MDM. The expressions of enTLRs and IFN- $\beta 1$ mRNA were up-regulated in both compounds and their combination. Additionally, these compounds also enhance M1-liked cytokine by up-regulated IL- 6 and down-regulated IL-10 and TGF- $\beta 1$, respectively. Therefore, sanguinarine and chelidonine enhance enTLR and IFN- $\beta 1$ expression and trend to stimulate the cell into M1-liked MDM.
\end{abstract}

Keywords: Monocyte-derived macrophage, sanguinarine, chelidonine, endosomal toll-like receptor, macrophage polarization

*Correspondence: nuchsupha.s@msu.ac.th; surasak.kk@msu.ac.th; +66 043-754-245

(Received: May 23, 2020; accepted: October 21, 2020)

Citation: Sunthamala N, Suebsamran C, Khruaphet N, et al. Sanguinarine and Chelidonine Synergistically Induce Endosomal Tolllike Receptor and M1-Associated Mediators Expression. J Pure Appl Microbiol. 2020;14(4):2351-2361. doi: 10.22207/JPAM.14.4.13

(C) The Author(s) 2020. Open Access. This article is distributed under the terms of the Creative Commons Attribution 4.0 International License which permits unrestricted use, sharing, distribution, and reproduction in any medium, provided you give appropriate credit to the original author(s) and the source, provide a link to the Creative Commons license, and indicate if changes were made. 


\section{INTRODUCTION}

The natural product is an essential source of medical capacity. Especially medicinal plant-derived natural products, it reveals various activities such as anti-microbial, anti-oxidant, anti-tumor, and anti-inflammation ${ }^{1-5}$. The active compounds, sanguinarine and chelidonine, are isoquinoline alkaloids derived from plants including Sanguinaria canadensis, Chelidonium majus, and other poppy-Fumaria species ${ }^{1,2}$. These compounds have been represented several activities in both in vitro and in vivo studies, including the antiinflammatory effect of sanguinarine on murine RAW264.7 macrophage cell line and cytokine production on animal mode ${ }^{1,6}$. Chelidonine shows the inhibition effect on nitric oxide production by murine RAW264.7 macrophage cell line ${ }^{7}$, and anti-tumor activities on several cancer cells ${ }^{2}$ such as head and neck cancer cell lines ${ }^{5}$ and mouse leukemic cell line $e^{4}$. Therefore, sanguinarine and chelidonine, which exhibit activities in various cell types including cancer cells, virus-derived cancer cells, and immune cells, might stimulate a distinct mechanism in several target cells of the treatment.

Macrophage is an important innate immune cell, which act as effective immune responses for infection and inflammation ${ }^{8}$. These cells play crucial roles in phagocytosis, antigen presentation, and cytokine secretion ${ }^{9,10}$. The toll-like receptors (TLRs) are essential innate pathogen recognition receptor that presents in macrophages, neutrophils, dendritic cells, and several cells ${ }^{8,11,12}$. The TLR recognized both extracellular and intracellular foreign materials, particularly endosomal TLR (enTLR), TLR3, TLR7/8, and TLR9, which are essentially responsible for virus infection ${ }^{8,11,13}$. Moreover, stimulations of TLR7 and TLR9 modulate the regulation of the antigen presentation by macrophages which enhances adaptive immune responses ${ }^{8}$. During enTLRs stimulation, several mediators are expressed depending on their adaptor proteins such as MyD88/NF-kb and/or TRIF/ IRF signaling pathways ${ }^{14}$. The trigger of MyD88 signaling pathway induces the expression of several pro-inflammatory cytokines depending on the polarization of macrophages ${ }^{15,16}$. The M1 macrophage produces pro-inflammatory cytokines such as IL-1 $\beta$, IL- 6 , and TNF- $\alpha$ whereas the $\mathrm{M} 2$ macrophage produces anti-inflammatory cytokines such as IL-4 and IL-10 $10^{17}$. Moreover, the stimulation of enTLRs via TRIF signaling pathway could induce the production of type I interferon (IFN) which plays crucial role in anti-viral activity ${ }^{12}$. Therefore, the study of sanguinarine and chelidonine on enTLR is still needed more information. This study aims to obtain the effects of sanguinarine and chelidonine on human monocyte-derived macrophage (MDM) and their antibacterial activity on Staphylococcus aureus DMST8840 by enhancing macrophage activity, stimulating of enTLRs, type I IFN, and cytokine expression toward M1 and M2-liked macrophages.

\section{MATERIALS AND METHODS}

Peripheral blood collection and PBMC isolation

The peripheral blood mononuclear cell (PBMC) were collected from five healthy volunteers, according to the approval of the Human Ethics Committee of Mahasarakham University (No. 057/2562). The healthy volunteers with normal body temperature and normal blood pressure, gave written consent for blood collection. The PBMC were separated by using Lymphoprep as the protocol (Stemcell Technologies, Oslo, Norway). Briefly, $25 \mathrm{~mL}$ of EDTA containing blood were overlayed to $15 \mathrm{~mL}$ of Lymphoprep, which was then centrifuged at 2,000 rpm for 20 minutes at room temperature. The Buffy coat was collected from the interphase and washed three times with 1xphosphate buffer saline (PBS). The PBMC were counted under hematocytometer ${ }^{18}$.

$\mathrm{CD}^{+} 4^{+}$monocyte isolation and monocyte-derived macrophage cultivation

$\mathrm{CD} 14^{+}$monocytes were isolated by using anti-human CD14 magnetic particles and BD IMag separator (BD Bioscience, San Jose, CA, USA). The purity of $\mathrm{CD} 14^{+}$monocytes was tested by $\mathrm{BD}$ FACScanto II using anti-human CD14 antibody (BD Bioscience, San Jose, CA, USA). The purity of $\mathrm{CD} 14^{+}$monocytes were tested by BD FACScanto II using anti-human CD14 antibody with cell purity higher than $95 \%$ in every experiment (data not showed). Monocytes from each volunteer were separately cultured in RPMI-1640 supplemented with antibiotic/antimycotic (Gibco, Thermo Scientific, CA, USA), and $10 \%$ fetal bovine serum (FBS) (Gibco, Thermo Scientific, CA, USA), under 
culture condition at $37^{\circ} \mathrm{C}, 5 \% \mathrm{CO}_{2}$, and humidity ${ }^{19}$. The culture media were supplemented with $50 \mu \mathrm{g} /$ $\mathrm{mL}$ of recombinant human GM-CSF (Peprotech, NJ, USA) for M1-liked MDM polarization, and $50 \mu \mathrm{g} /$ $\mathrm{mL}$ of IL-4 (Peprotech, NJ, USA) for M2-liked MDM polarization, respectively ${ }^{15,20}$. The $10 \mathrm{ng} / \mathrm{mL}$ of polyl:C (Invivogen, CA, USA) was treated to MDM for positive control of enTLR stimulation ${ }^{21}$.

Expression of CD14, CD16, enTLRs, iNOS, and cytokines mRNAs

After 6 days of culture, the CD14 monocytes were differentiated into MDM and the total RNA was extracted by using RNA-Xpress reagent according to manufacturer instruction (Himedia, Mumbai, India). Briefly, the MDM cell pellet was lysed in RNA-Xpress reagent, and the chloroform was added and centrifuged at 13,000 $\mathrm{rpm}$ for 15 minutes at $4^{\circ} \mathrm{C}$. The aqueous phase containing RNA were collected and precipitated with isopropanol centrifugation. The RNA pellets were washed with $75 \%$ ethanol and resuspended in RNase free water (Himedia, Mumbai, India). Total RNA was reverse transcribed to CDNA by using RevertAid $\mathrm{H}$ Minus First Strand cDNA Synthesis Kit (Thermo Scientific, CA, USA).

The expression of CD14 and CD16 mRNA were determined by SYBR green real-time PCR reagent (Biorad, CA, USA) using Applied Biosystems 7500 Real-Time PCR System (Fisher Scientific, CA, USA). The expressions of enTLRs, cytokines and iNOS were performed as same as the detection of CD14 and CD16. The mRNA expression was normalized by GAPDH internal control and calculated its relative expression by using $2^{-\Delta \Delta C T}$ methods ${ }^{22}$.

\section{Cell viability assay}

The cytotoxic activities of sanguinarine and chelidonine (Sigma-Aldrich,) on monocyte were performed by 3-(4,5-dimethylthiazol-2-yl)2,5-diphenyltetrazolium bromide (MTT) assay (Gibco, Thermo Scientific, CA, USA). Briefly, the various concentrations of compounds from 0-100 $\mu \mathrm{M}$ were added at day 6 of cultured MDM and incubated for $48 \mathrm{~h}$. The $12 \mathrm{mM}$ of MTT was added to the culture system and incubated for $4 \mathrm{~h}$ at the dark before adding Dimethyl sulfoxide (DMSO) to dissolve the formazan crystals. The viability of MDM was detected at $540 \mathrm{~nm}$ spectrophotometry and calculated the \%viability comparing to cell control ${ }^{23}$.

\section{Phagocytosis activity of MDM}

The subtoxic concentration of compounds was added to cultured MDM at day 6 and incubated for $48 \mathrm{~h}$. The bacterium Staphylococcus aureus DMST8840 were inoculated to MDM culture at $\mathrm{MOI}$ of 30 . After co-incubation for 1 $h$, the MDM were washed and lysed by using $1 \%$ SDS, and viable bacterial cell were counted by drop plate on TSA plate and calculated of CFU/100 cell macrophages $^{24,25}$.

The killing activity of MDM was determined after co-incubation of MDM and Staphylococcus aureus DMST8840 for $3 \mathrm{~h}$ at MOI of 30 . The incubated MDM were washed and lysed by using $1 \%$ SDS after co-incubation for 1 $h$, and viable bacterial cell were counted by drop plate on TSA plate and calculated of CFU/100 cell macrophages ${ }^{24,25}$.

\section{Nitric oxide production assay}

The production of nitric oxide (NO) was examined by using the Griess assay ${ }^{23}$. The supernatant of co-incubation of MDM and Staphylococcus aureus DMST8840 were collected and subsequently detected the production of NO by adding Griess reagent, sulfanilamide and N-1naphthyl ethylenediamine dihydrochloride (NED) under acidic conditions (Promega, Madison, WI, USA). The concentration of NO was then compared to sodium nitrite standard concentration ${ }^{23}$.

\section{Statistical analysis}

Statistical analysis of this study was performed using GraphPad Prism Software (GraphPad Soft Inc. La Jolla, CA, USA). The t-test and one-way analysis of variance (ANOVA) analysis with Tukey posttest were used. All data were represented in mean \pm SD. The significant difference was considered at $p$-value $<0.05$.

\section{RESULTS}

Expression of CD14 and CD16 in monocytederived macrophages

$\mathrm{CD}_{14}{ }^{+}$monocytes were cultured for 6 days. The monocytes and MDM morphology were showed in Fig. $1 \mathrm{~A}$ and $1 \mathrm{~B}$, respectively. The mRNA expression of CD14 monocyte was significantly decreased, whereas the CD16 macrophage marker was considerably increased after culture for 6 days comparing to day 1 . The results revealed that, the monocytes were differentiated into MDM after cultured at day 6 (Fig. 1C and 1D). 


\section{Cytotoxic activity of sanguinarine and chelidonine on monocyte-derived macrophages}

Monocyte-derived macrophages were treated with $0-100 \mu \mathrm{M}$ in each sanguinarine and chelidonine. The result shows no significant difference on cell viability in all concentrations when compared to the cell control. Therefore, the optimum concentration of sanguinarine and chelidonine were $6.25 \mu \mathrm{M}$. These optimum concentrations provide over $90 \%$ cell viability and were selected for further experiments (Fig. 1E and $1 \mathrm{~F})$.
A

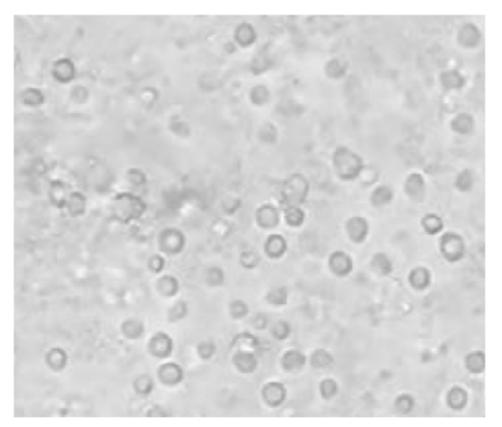

C
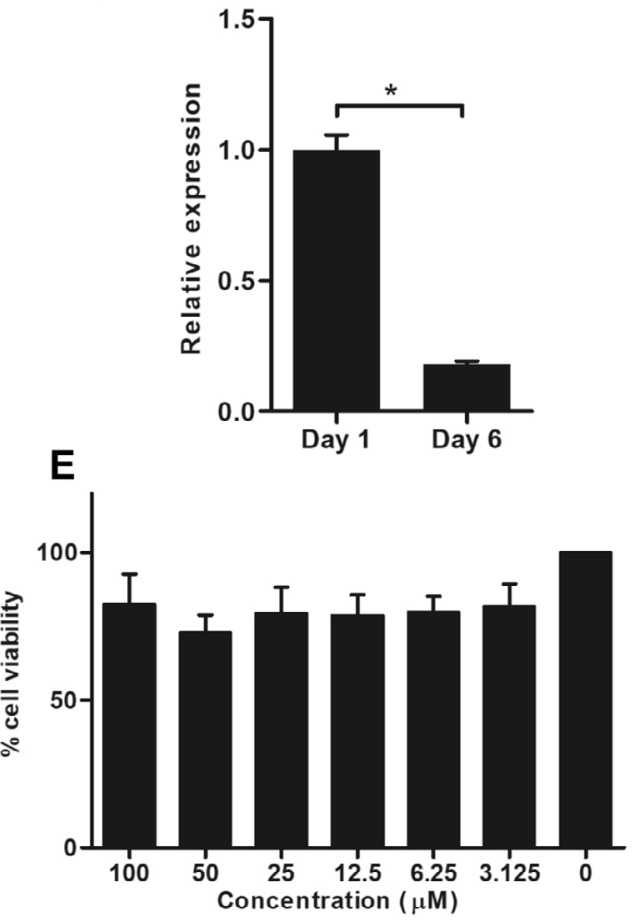

B

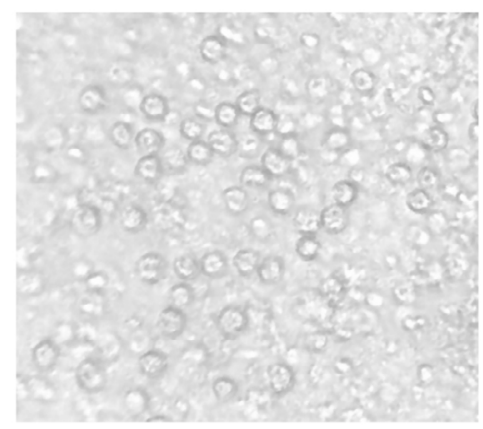

D
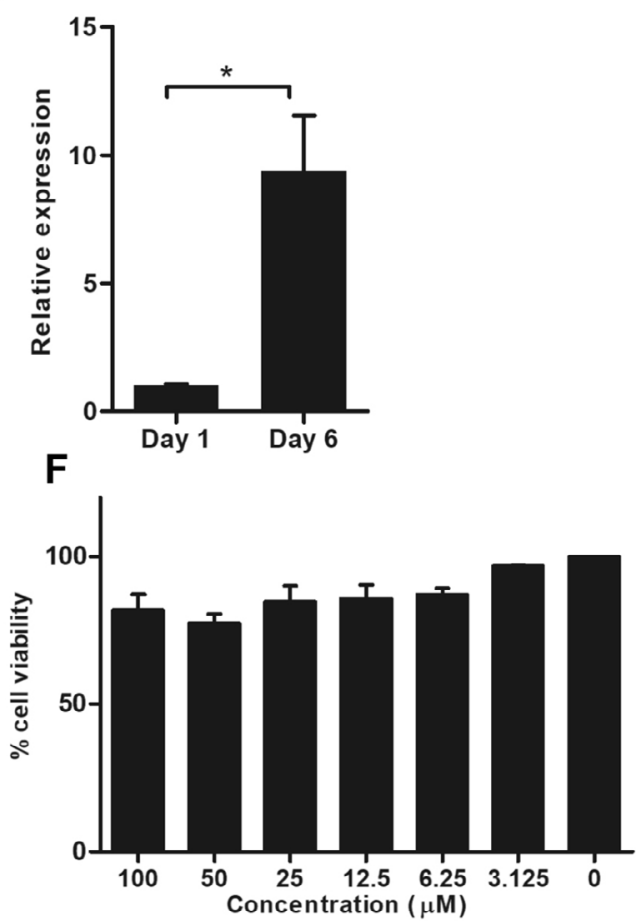

Fig. 1. Expression of CD14 and CD16 in monocyte-derived macrophages after cultivation and cell viability of monocyte-derived macrophages in treatment with sanguinarine and chelidonine

Cell morphology of $\mathrm{CD} 14^{+}$monocytes at day 1 (A) and monocyte-derived macrophages at day 6 of culture (B). The mRNA expression of CD14 and CD16 were examined after day 6 of cultivation. The CD14 mRNA expression represent monocyte marker (C). The CD16 mRNA expression represent macrophage marker (D). The cell viability of monocyte-derived macrophages after treated with 0-100 $\mu \mathrm{M}$ of sanguinarine $(\mathrm{E})$ and chelidonine $(\mathrm{F})$ were determined by MTT assay. The experiments were performed in triplicate and used five healthy volunteers. The monocytes from each volunteers were separately cultured and tested. $(*)$ represented significant difference at $\mathrm{p}$-value $<0.05$. 


\section{Antibacterial activity of sanguinarine and chelidonine against Staphylococcus aureus}

The phagocytic activity and nitric oxide production were examined to determine the antibacterial properties of MDM. The MDM were treated with $6.25 \mu \mathrm{M}$ of each sanguinarine, chelidonine and mixed $6.25 \mu \mathrm{M}$ of sanguinarine and $6.25 \mu \mathrm{M}$ of chelidonine for $48 \mathrm{~h}$. After treatment, the MDM were subsequently co-cultured with S. aureus DMST 8840 for $1 \mathrm{~h}$ and determined the phagocytosis activity. The phagocytic activity of MDM was significantly increased in both compounds and their mixed when compared to the polyl: $C$ treatment and the cell control. Indicating that sanguinarine and chelidonine have ability to enhance the phagocytic activity of MDM (Fig. 2A). Interestingly, sanguinarine, chelidonine and their mixed revealed a higher number of bacterial survival than the MDM treated by polyl:C, and the cell control after co-culture for $3 \mathrm{~h}$ (Fig. 2B). Nitric
A
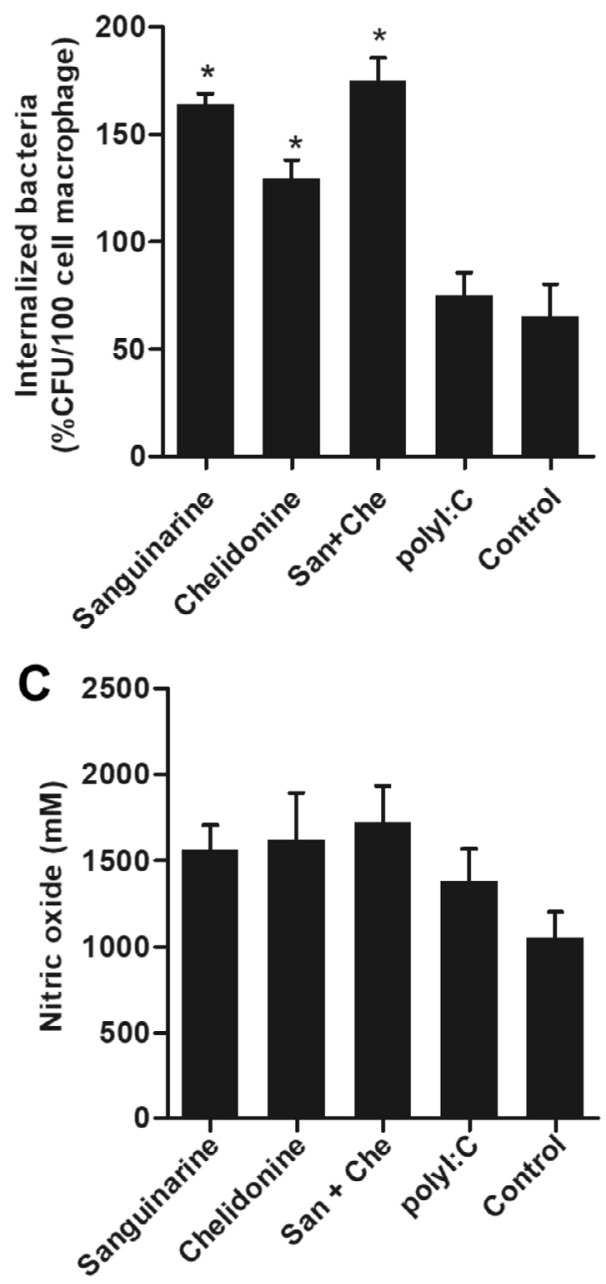

B

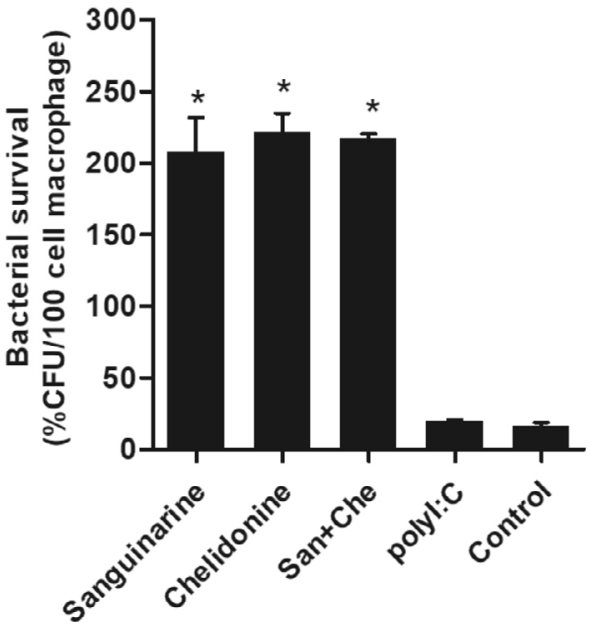

D

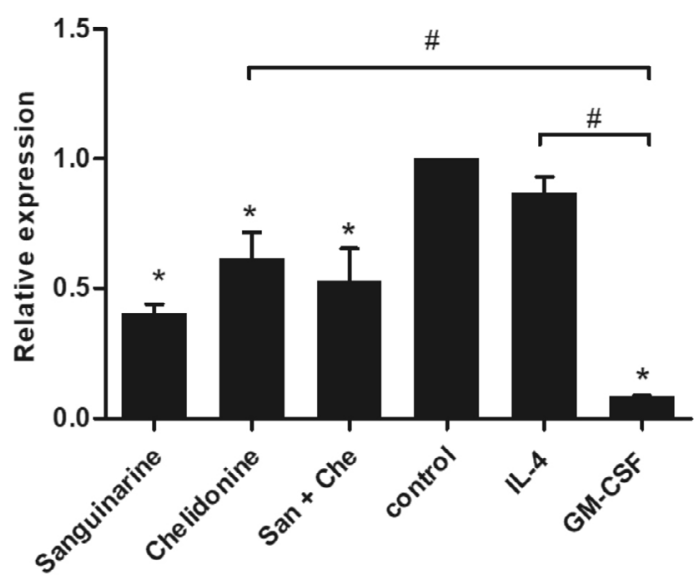

Fig. 2. Antibacterial activity of sanguinarine and chelidonine against Staphylococcus aureus Monocyte-derived macrophages were treated with optimum concentration at $6.25 \mu \mathrm{M}$ of sanguinarine and chelidonine for $48 \mathrm{~h}$ subsequently co-culture with Staphylococcus aureus for $1 \mathrm{~h}$. The phagocytosis activity of MDM was determined in both compounds and their mixed compared to polyl:C treatment and cell control (A). The killing activity was examined after co-culture with Staphylococcus aureus for $3 \mathrm{~h}$ (B). Nitric oxide production after co-culture of MDM and bacteria were detected (C). The expression of iNOS mRNA was showed (D). The experiments were performed in triplicate and used five healthy volunteers. The monocytes from each volunteers were separately cultured and tested. $\left({ }^{*}\right)$ represented significant difference when compared to control. (\#) represented significant difference between groups, $\mathrm{p}$-value $<0.05$. 
oxide production after co-culture of MDM and bacteria were slightly increased in sanguinarine, chelidonine and their mixed treatment when compared to the cell control (Fig. 2C). Moreover, the expression of iNOS mRNA was significantly down-regulated in sanguinarine, chelidonine
A

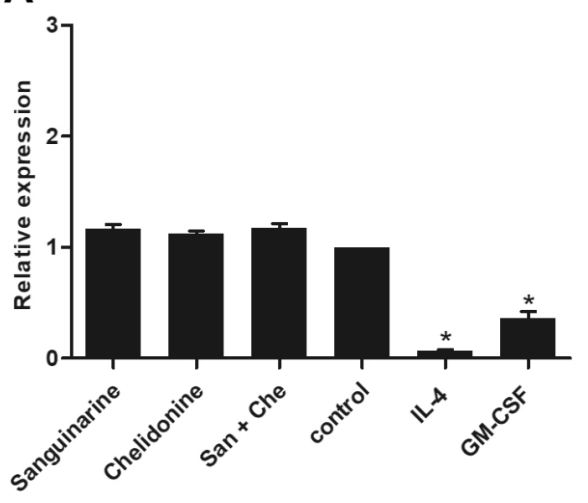

C

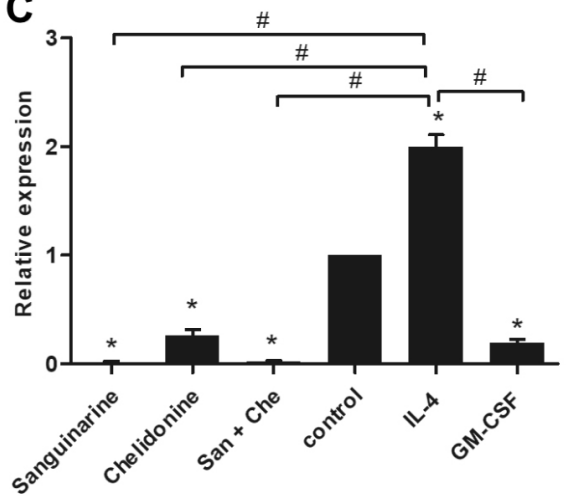

B

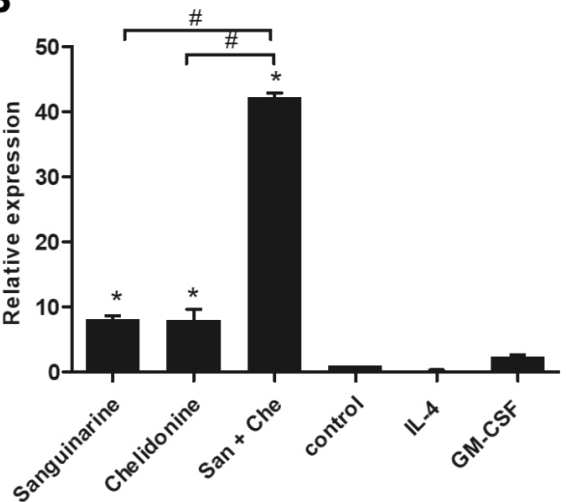

D

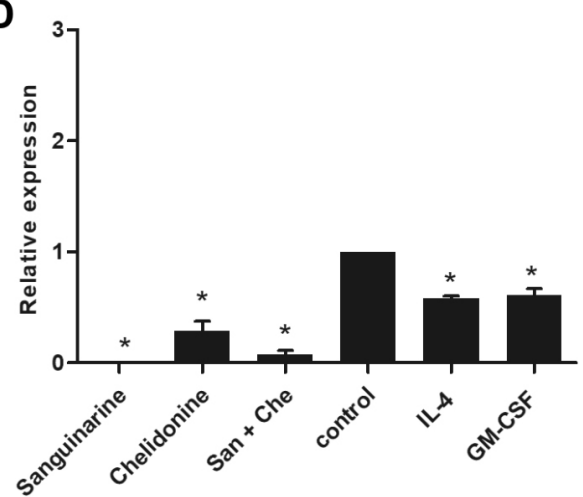

E

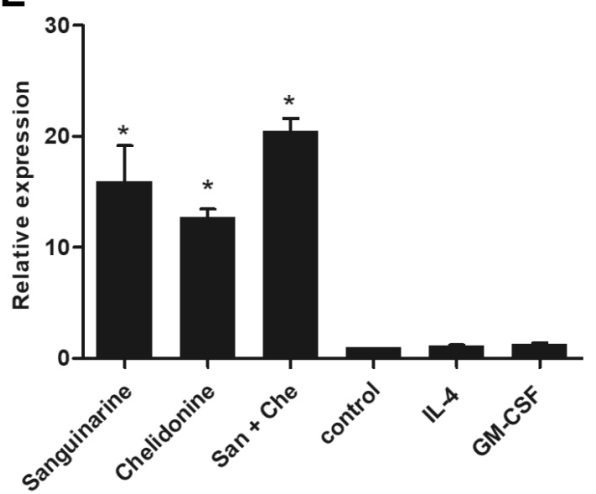

Fig. 3. The expression of $M 1$ and $M 2$ macrophage-associated cytokines and type I IFN

The expression of $\mathrm{M} 1$ and macrophage-associated cytokines were determined in MDM stimulating with sanguinarine, chelidonine, and their mixed compared to CD14+ cell culture in GM-CSF or IL-4 culture conditions, representing as M1 and M2-liked MDM, respectively. The expression of IL-1 $\beta$ (A) and IL-6 (B) have represented the M1-liked MDM properties. The expression of IL-10 (C) and TGF- $\beta 1$ (D) have represented the M2-liked MDM-associated cytokines. The expression of type I IFN, IFN- $\beta 1$ was showed in (E). The expression values were showed in relative expression comparing to cell control. The experiments were performed in triplicate and used five healthy volunteers. The monocytes from each volunteers were separately cultured and tested. $\left({ }^{*}\right)$ represented significant difference when compared to control. (\#) represented significant difference between groups, p-value $<0.05$. 
and their mixed treated MDM when compare to the IL-4 treated MDM and the cell control. This down-regulation of iNOS MRNA exhibited the same trend as GM-CSF treated MDM (Fig. 2D). MDM was cultured in GM-CSF and IL-4 containing culture media to induce cell differentiation into M1-liked and M2-liked macrophage characteristic, respectively. M1-liked MDM showed significantly down-regulated of iNOS when compare to cell control, whereas M2-liked MDM was no difference (Fig. 2D).

Sanguinarine and chelidonine alter the expression of M1 and M2 macrophage-associated cytokines

The expression of $\mathrm{M} 1$ and macrophageassociated cytokines were determined in MDM stimulated with sanguinarine, chelidonine, and their mixed compared to $\mathrm{CD} 14^{+}$cell culture in GM-CSF or IL-4 conditions, representing as M1 and M2-liked MDM, respectively. The expressions of IL$1 \beta$ and IL- 6 have represented the M1-liked MDM properties. The expression of IL-1 $\beta$ mRNA was not difference in all treatments (Fig. 3A), whereas IL-6 was significantly up-regulated in MDM treated with sanguinarine, chelidonine, and their mixed when compared to cell control (Fig. 3B). Interestingly, the expression of M2-liked MDMassociated cytokines, IL-10 was significantly downregulated in MDM treated with sanguinarine, chelidonine, and their mixed comparing to cell control and IL-4 treated MDM (Fig. 3C). The expression of TGF- $\beta 1$ was also down-regulated in MDM treated with sanguinarine, chelidonine,
A

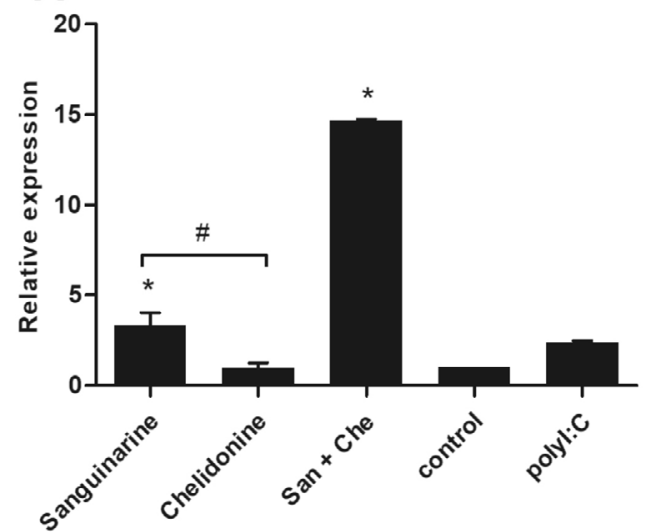

C

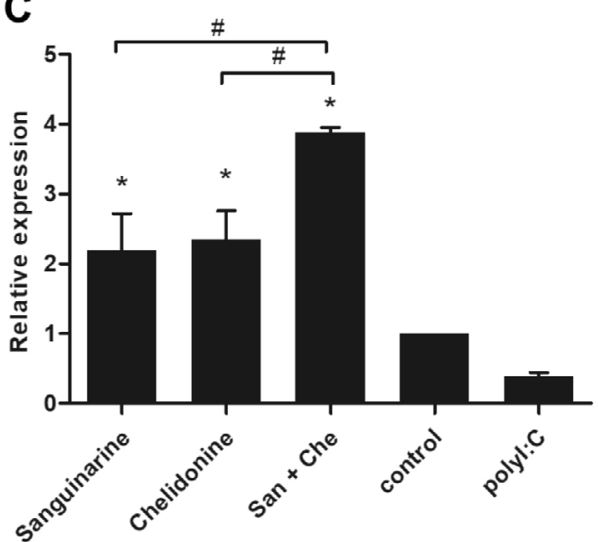

\section{B}

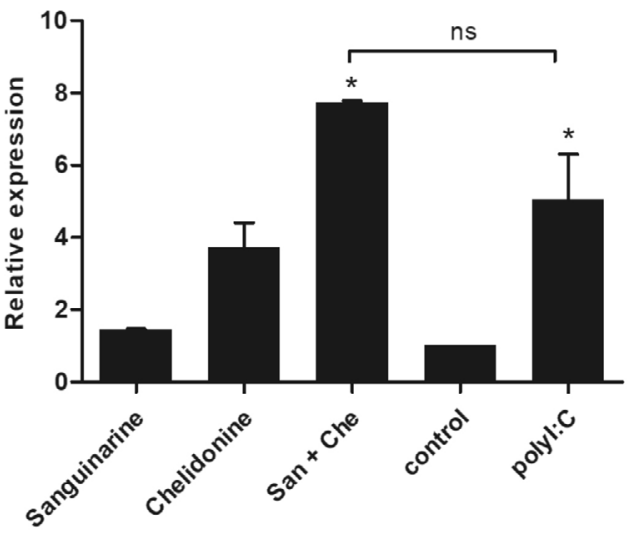

D

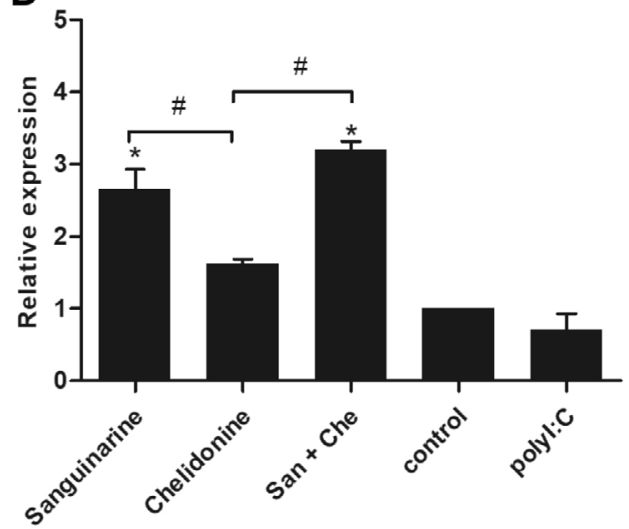

Fig. 4. Synergistic effect of sanguinarine and chelidonine on the expression of endosomal TLRs

The expression of endosomal TLR mRNA was determined by SYBR green real-time PCR after treatment with sanguinarine and chelidonine for $24 \mathrm{~h}$. The expression of TLR3 (A), TLR9 (B), TLR7 (C), and TLR8 (D) were represented in relative expression comparing to cell control. The experiments were performed in triplicate and used five healthy volunteers. The monocytes from each volunteers were separately cultured and tested. $(*)$ represented significant difference when compared to control. (\#) represented significant difference between groups, $\mathrm{p}$-value $<0.05$. 
and their mixed comparing to cell control and IL-4 treated MDM (Fig. 3D). These suggested that sanguinarine and chelidonine synergistically up-regulated IL-6 but down-regulated IL-10 and TGF- $\beta 1$. The stimulations of sanguinarine and chelidonine trend to enhance monocyte-derived macrophage to M1-liked polarization.

Sanguinarine and chelidonine synergistically upregulate enTLRs mRNA expression and enhanced anti-viral activity

Treatment of MDM with chelidonine has not altered the expression of TLR3 whereas sanguinarine and their mixed significantly upregulated TLR3 mRNA expression comparing to control and positive control Polyl:C treatment (Fig. 4A). The expression of TLR9 mRNA also showed the similar pattern to the TLR3 expression. In addition, the TLR9 expression that was induced by sanguinarine, chelidonine, and their mixed higher than cell control. The TLR9 upregulation also found in positive control Polyl:C treatment (Fig. 4B). The expression of TLR7 and TLR8 mRNA were represented in the same pattern. The mRNA expressions of TLR7 and TLR8 were up-regulated in both sanguinarine and chelidonine treatments. Moreover, the combination of the two compounds was significantly enhanced the expression of TLR7 and TLR8 mRNAs (Fig. 4C and 4D, respectively). The result suggested that sanguinarine and chelidonine modulate the expression of enTLRs, especially the combination of these compounds considerably enhanced the expression of four enTLRs. The upregulation of endosomal TLRs was significantly facilitated the up-regulation of IFN- $\beta 1$, the type I interferon, by sanguinarine, chelidonine, and their mixed treatments (Fig. 3E). Hence, sanguinarine, chelidonine, and their mixed might stimulate the enTLR expression and enhance anti-viral activity in MDM.

\section{DISCUSSION}

The three main subsets of human peripheral monocyte include, classical monocytes (CD $14^{++}$CD 16-), intermediate monocytes $\left(\mathrm{CD} 14^{++} \mathrm{CD} 16^{+}\right)$, and non-classical monocytes $\left(\mathrm{CD} 14^{+} \mathrm{CD} 16^{++}\right)^{26}$. The monocytes used in this study were collected from $\mathrm{CD} 14^{+}$cells from total human peripheral blood, which represented high purity after isolation with CD14 magnetic beads (Fig. 1A). Monocytes were differentiated into macrophage by cultivation in medium and classified as CD14 ${ }^{\text {low }} \mathrm{CD}_{16}{ }^{+9}$ (Fig. $1 \mathrm{C}$ and 1D). The treatments of sanguinarine and chelidonine on cell viability of MDM were found no significant difference in all tested concentrations (Fig. 1E and 1F). These results concurred with other studies that use human cells, including human leukocytes ${ }^{27}$ and human neutrophil ${ }^{28}$. Moreover, these compounds also treated on murine macrophage Raw264.729, human monocyte cell line THP- ${ }^{30}$, and murine peritoneal macrophage ${ }^{6,31}$. In this study, the MDM cell viability was not affected by sanguinarine and chelidonine whereas their phagocytic activity was altered by these compounds (Fig. 2A and 2B). Moreover, the capacity of compounds inducing NO production and expression of iNOS mRNA have concurred to some study (Fig. 2C and 2D). Alkaloid from Chelidonium majus exhibits an inhibitory effect on LPS induces NO production and iNOS expression in murine macrophage RAW264.7 ${ }^{7}$. Chelidonine significantly suppresses LPS induced pro-inflammatory mediators including $\mathrm{NO}$ and PGE2 production, and iNOS and COX2 mRNA and protein expression in murine RAW264.7 macrophage $^{32}$. The expression of iNOS mRNA is regulated by NO concentration on macrophage ${ }^{37}$.

Chelidonine inhibits TNF- $\alpha$ induced inflammation by suppressing NF- $\kappa B$ in HCT116 cells ${ }^{3}$ and strongly suppresses the expression of eotaxin-2, IL-4, and IL-13 in bronchoalveolar lavage fluid of asthmatic mice ${ }^{33}$. While, sanguinarine suppresses the production of IL-1 $\beta, \mathrm{IL}-6$, and TNF- $\alpha$ in a rat middle cerebral artery occlusion model $^{1}$. Sanguinarine also suppresses CCL2 and IL- 6 expression after LPS stimulation of human THP-1 cell ${ }^{30}$ and inhibits LPS induced PGE2 COX2 in murine peritoneal macrophage ${ }^{6}$. Sanguinarine suppresses LPS induced TLR4/ NF-KB pathway in H9c2 cardiomyocytes and attenuated cytokines product after stimulation of cell with LPS, IL-1 $\beta$, IL-6, TNF- $\alpha^{34}$. In addition, Sanguinarine also inhibits the MAPK pathway and alters inflammatory cytokine production in murine peritoneal macrophage ${ }^{31}$. Sanguinarine and chelidonine exhibit anti-inflammatory effects by suppressing pro-inflammatory cytokines and chemokine production. Particularly in study of effect on cell stimulating by LPS can inhibit TLR4/ NF-KB pathway. Suggesting that these compounds involve to TLR stimulation or TLR gene expression. 
Macrophage can be stimulated into two different functional polarizations including the classical M1 macrophage and the $M 2$ macrophage ${ }^{15,35}$. The M1 macrophage polarization is induced by microbial stimuli and cytokines such as IFN- - , TNF- $\alpha$, and GM-CSF. The effector mediators of $\mathrm{M} 1$ macrophage are pro-inflammatory cytokines, IL-1 $\beta$, IL-6, IL-12, IL-23, and TNF- $\alpha^{20}$. The M1 macrophage exhibits anti-intracellular bacteria, anti-infection, and anti-tumor by increasing cytotoxic activity against tumor cells ${ }^{15}$. In contrast, the activators of M2 macrophage polarization are IL-4, IL-10, IL-13, and TGF- $\beta$. The M2 macrophage represents less capacity of antigen presenting cells and attenuates $T$ helper 1 response ${ }^{15,36}$. In addition, the M2 macrophage is involved in angiogenesis and tissue healing ${ }^{35}$. According to our study, the expression of cytokines based on M1-liked and M2-liked MDM properties was determined. The study revealed a synergistic effect of sanguinarine and chelidonine on up-regulation of IL-6 (Fig. 3B) and down-regulation of IL-10 and TGF- $\beta 1$ (Fig. $3 C$ and $3 D$ ), suggesting that sanguinarine and chelidonine might involve in the M1-liked polarization of MDM. Moreover, high iNOS expression mediates nitration of tyrosine residues in IRF5 protein, leads to suppression of macrophage polarized into $\mathrm{M}^{37}$.

Sanguinarine and chelidonine do not only effect on cytokine production, but these compounds also exhibit activities on enTLRs expression. The enTLRs, including TLR3, TLR7, TLR8, and TLR9, are expressed by several cells such as human macrophage ${ }^{8}$, neutrophil ${ }^{11}$, and plasmacytoid dendritic cell ${ }^{12}$. TLR agonist enabling enhanced phagocytosis by macrophage and dendritic cell ${ }^{38,39}$ and also induce cell maturation by altering phagocytosis activity into antigen presentation ${ }^{40}$. TLR9 agonist is cytidine-phosphateguanidine (CpG)-containing DNA; some small molecules have the ability to inhibit TLR7 and TLR9 signaling ${ }^{13}$. The stimulation of TLR7 and TLR9 ligands increase phagocytosis and apoptotic target cell by macrophage. The ligation of TLR7 and TLR9 suppresses the expression of CD86 and $\mathrm{MHC}$ class II, which is associated with decreasing of antigen presentation and proliferation of $\mathrm{T}$ cell ${ }^{8}$. The exposure of TLR7 and TLR9 ligands prolongs macrophage cell viability whereas the exposure of TLR3 or TLR4 ligand reduces macrophage cell viability. The exposure of TLR7 and TLR9 ligand induces macrophage to phagocytic long-live cell and decrease the ability of antigen presentation and drive macrophage into M2 polarization ${ }^{8}$. Stimulation of TLR7 and TLR9 ligands enhances the expression of type I interferon (IFN- $\alpha$ ) in plasmacytoid DC and enhances anti-viral state ${ }^{12}$. In this study, sanguinarine, chelidonine and their mixed enhance the expression of all four enTLRs (Fig. 4A, 4B, 4C, and 4D). In addition, sanguinarine, chelidonine and their mixed treatments also induce IFN- $\beta 1$ mRNA expression (Fig. 3E), suggesting that sanguinarine and chelidonine facilitate an antiviral activity by inducing enTLRs expression and its downstream mediator in MDM.

Taken together, the stimulation of MDM by sanguinarine and chelidonine reveals two main mechanisms. Firstly, these compounds synergistically enhanced IL- 6 expression and down-regulated IL-10 and TGF- $\beta 1$, which involve an induction of MDM polarization into M1-liked property. Lastly, sanguinarine and chelidonine stimulate the expression of enTLRs including TLR3, TLR7/8, and TLR9, which leads to an upregulation of IFN- $\beta 1$, an important antiviral mediator. These suggesting that this study might show a specific novel mechanism in human MDM on M1 polarization, enTLRs and its downstream mediators.

\section{ACKNOWLEDGMENTS}

We greatly thank research team members of Mahasarakham University for helpful discussion. We would like to thank the Department of Biology, Faculty of Science, and Central Laboratory, Mahasarakham University for providing instruments.

\section{CONFLICT OF INTEREST}

The authors declare that there is no conflict of interest.

\section{AUTHORS' CONTRIBUTION}

NS(NS1) and N.S.(NS2) designed the experiments. NS1, CS, NK, NS2, JJ, SK, RT, and SC performed the experiments. NS1 and NS2 analyzed the data. NS1 wrote the manuscript. All authors read and approved the manuscript. 


\section{FUNDING}

This study was financially supported by the Faculty of Science, Mahasarakham University (Grant year 2019, No. 004/2562) to NS1.

\section{DATA AVAILABILITY}

The datasets generated and/or analyzed during the current study are available in the Figshare database repository, https://figshare. com/articles/Project_Sanguinarine_and_ Chelidonine_on_macrophages/12362018.

\section{ETHICS STATEMENT}

The peripheral blood mononuclear cell (PBMC) were collected from 5 healthy volunteers, according to the approval of the Human Ethics Committee of Mahasarakham University (No. 057/2562).

\section{REFERENCES}

1. Wang $Q$, Dai $P$, Bao $\mathrm{H}$, et al. Anti-inflammatory and neuroprotective effects of sanguinarine following cerebral ischemia in rats. Exp Ther Med. 2017;13(1):263-268. doi: 10.3892/etm.2016.3947

2. Gaziano R, Moroni G, Bue C, Miele MT, SinibaldiVallebona P, Pica F. Antitumor effects of the benzophenanthridine alkaloid sanguinarine: Evidence and perspectives. World J Gastrointest Oncol. 2016;8(1):30-39. doi: 10.4251/wjgo.v8.i1.30

3. Zhang $\mathrm{ZH}, \mathrm{Mi}$, Wang KS, et al. Chelidonine inhibits TNF-a-induced inflammation by suppressing the NF-KB pathways in HCT116 cells. Phytother Res. 2018;32(1):65-75. doi: 10.1002/ptr.5948

4. Kaminskyy V, Lin KW, Filyak Y, Stoika R. Differential effect of sanguinarine, chelerythrine and chelidonine on DNA damage and cell viability in primary mouse spleen cells and mouse leukemic cells. Cell Biol Int. 2008;32(2):271-277. doi: 10.1016/j.cellbi.2007.09.004

5. Herrmann R, Roller J, Polednik C, Schmidt M. Effect of chelidonine on growth, invasion, angiogenesis and gene expression in head and neck cancer cell lines. Oncol Lett. 2018;16(3):3108-3116. doi: 10.3892/ ol.2018.9031

6. Li W, Li H, Mu Q, Zhang H, Yao H, Li J, Niu X. Protective effect of sanguinarine on LPS-induced endotoxic shock in mice and its effect on LPS-induced COX-2 expression and COX-2 associated $\mathrm{PGE}_{2}$ release from peritoneal macrophages. Int Immunopharmacol. 2014;22(2):311317. doi: 10.1016/j.intimp.2014.07.017

7. Park JE, Cuong TD, Hung TM, et al. Alkaloids from Chelidonium majus and their inhibitory effects on LPSinduced NO production in RAW264.7 cells. Bioorg Med Chem Lett. 2011;21(23):6960-6963. doi: 10.1016/j. bmcl.2011.09.128

8. Celhar T, Pereira-Lopes S, Thornhill SI, et al. TLR7 and TLR9 ligands regulate antigen presentation by macrophages. Int Immunol. 2016;28(5):223-232. doi: 10.1093/intimm/dxv066

9. Ginhoux F, Guilliams M. Tissue-Resident Macrophage Ontogeny and Homeostasis. Immunity. 2016;44(3):439449. doi: 10.1016/j.immuni.2016.02.024

10. Kelly A, Gunaltay S, McEntee CP, et al. Human monocytes and macrophages regulate immune tolerance via integrin $\alpha v \beta 8$-mediated TGF $\beta$ activation. J Exp Med. 2018;215(11):2725-2736. doi: 10.1084/ jem.20171491

11. Lood C, Arve S, Ledbetter J, Elkon KB. TLR7/8 activation in neutrophils impairs immune complex phagocytosis through shedding of FcgRIIA.J Exp Med. 2017;214(7):2103-2119. doi: 10.1084/jem.20161512

12. Berghofer B, Haley G, Frommer T, Bein G, Hackstein $\mathrm{H}$. Natural and synthetic TLR7 ligands inhibit CpG-Aand CpG-C-oligodeoxynucleotide-induced IFN-alpha production. J Immunol. 2007;178(7):4072-4079. doi: 10.4049/jimmunol.178.7.4072

13. Lamphier M, Zheng W, Latz E, et al. Novel small molecule inhibitors of TLR7 and TLR9: mechanism of action and efficacy in vivo. Mol Pharmacol. 2014;85(3):429-440. doi: 10.1124/mol.113.089821

14. Trinchieri G, Sher A. Cooperation of Toll-like receptor signals in innate immune defence. Nat Rev Immunol. 2007;7(3):179-190. doi: 10.1038/nri2038

15. Murray PJ, Allen JE, Biswas SK, et al. Macrophage activation and polarization: nomenclature and experimental guidelines. Immunity. 2014;41(1):14-20. doi: 10.1016/j.immuni.2014.06.008

16. Mosser DM, Edwards JP. Exploring the full spectrum of macrophage activation. Nat Rev Immunol. 2008;8(12):958-969. doi: 10.1038/nri2448

17. Mantovani A, Sica A, Sozzani S, Allavena P, Vecchi A, Locati $M$. The chemokine system in diverse forms of macrophage activation and polarization. Trends Immunol. 2004;25(12):677-686. doi: 10.1016/j. it.2004.09.015

18. Muller G, Kerkhoff C, Hankowitz J, et al. Effects of purinergic agents on human mononuclear phagocytes are differentiation dependent. Implications for atherogenesis. Arterioscler Thromb. 1993;13(9):13171326. doi: 10.1161/01.ATV.13.9.1317

19. Lenart $M$, Rutkowska-Zapala $M$, Szatanek $R$, et al. Reprint of: Alterations of TRIM21-mRNA expression during monocyte maturation. Immunobiology. 2017;222(6):841-845. doi: 10.1016/j. imbio.2017.05.005

20. Steevels TA, Meyaard L. Immune inhibitory receptors: Essential regulators of phagocyte function. Eur J Immunol. 2011;41(3):575-587. doi: 10.1002/ eji.201041179

21. Sunthamala N, Thierry F, Teissier S, et al. E2 proteins of high risk human papillomaviruses down-modulate STING and IFN-K transcription in keratinocytes. PLOS ONE. 2014;9(3):e91473. doi: 10.1371/journal. pone. 0091473

22. Livak KJ, Schmittgen TD. Analysis of relative gene expression data using real-time quantitative PCR and the $2^{-\Delta \Delta C T}$ Method. Methods. 2001;25(4):402-408. doi: 10.1006/meth.2001.1262

23. Yang EJ, Yim EY, Song G, Kim GO, Hyun CG. Inhibition of nitric oxide production in lipopolysaccharide-activated 
RAW 264.7 macrophages by Jeju plant extracts. Interdiscip Toxicol. 2009;2(4):245-249. doi: 10.2478/ v10102-009-0022-2

24. Bartlett DB, Shepherd SO, Wilson OJ, et al. Neutrophil and Monocyte Bactericidal Responses to 10 Weeks of Low-Volume High-Intensity Interval or ModerateIntensity Continuous Training in Sedentary Adults. Oxid Med Cell Longev. 2017;2017:8148742. doi: 10.1155/2017/8148742

25. Borges AR, Santos PN, Furtado AF, Figueiredo RC. Phagocytosis of latex beads and bacteria by hemocytes of the triatomine bug Rhodnius prolixus (Hemiptera: Reduvidae). Micron. 2008;39(4):486-494. doi: 10.1016/j.micron.2007.01.007

26. Ziegler-Heitbrock L, Ancuta P, Crowe S, et al. Nomenclature of monocytes and dendritic cells in blood. Blood. 2010;116(16):e74-80. doi: 10.1182/ blood-2010-02-258558

27. Vavreckova C, Ulrichova J, Hajduch M, Grambal F, Weigl E, Simanek V. Effect of quaternary benzo[c] phenanthridine alkaloids sanguinarine, chelerythrine and fagaronine on some mammalian cells. Acta Univ Palacki Olomuc Fac Med. 1994;138:7-10.

28. Agarwal S, Piesco NP, Peterson DE, et al. Effects of sanguinarium, chlorhexidine and tetracycline on neutrophil viability and functions in vitro. $J$ Periodontal Res. 1997;32(3):335-344. doi: 10.1111/j.16000765.1997.tb00542.x

29. Vrba J, Orolinova E, Ulrichova J. Induction of heme oxygenase- 1 by Macleaya cordata extract and its constituent sanguinarine in RAW264.7 cells. Fitoterapia. 2012;83(2):329-335. doi: 10.1016/j. fitote.2011.11.022

30. Pencikova K, Kollar P, Muller Zavalova V, Taborska E, Urbanova J, Hosek J. Investigation of sanguinarine and chelerythrine effects on LPS-induced inflammatory gene expression in THP-1 cell line. Phytomedicine. 2012;19(10):890-895. doi: 10.1016/j. phymed.2012.04.001

31. Niu X, Fan T, Li W, Xing W, Huang $H$. The antiinflammatory effects of sanguinarine and its modulation of inflammatory mediators from peritoneal macrophages. Eur J Pharmacol. 2012;689(1-3):262269. doi: 10.1016/j.ejphar.2012.05.039

32. Liao W, He X, Yi Z, Xiang W, Ding Y. Chelidonine suppresses LPS-Induced production of inflammatory mediators through the inhibitory of the TLR4/NF-KB signaling pathway in RAW264.7 macrophages. Biomed Pharmacother. 2018;107:1151-1159. doi: 10.1016/j. biopha.2018.08.094

33. Kim SH, Hong JH, Lee YC. Chelidonine, a principal isoquinoline alkaloid of Chelidonium majus, attenuates eosinophilic airway inflammation by suppressing IL-4 and eotaxin-2 expression in asthmatic mice. Pharmacol Rep. 2015;67(6):1168-1177. doi: 10.1016/j. pharep.2015.04.013

34. Meng YY, Liu Y, Hu ZF, et al. Sanguinarine Attenuates Lipopolysaccharide-induced Inflammation and Apoptosis by Inhibiting the TLR4/NF-KB Pathway in H9c2 Cardiomyocytes. Curr Med Sci. 2018;38(2):204211. doi: 10.1007/s11596-018-1867-4

35. Mantovani A, Sica A, Locati M. Macrophage polarization comes of age. Immunity. 2005;23(4):344-346. doi: 10.1016/j.immuni.2005.10.001

36. Gordon S. Alternative activation of macrophages. Nat Rev Immunol. 2003;3(1):23-35. doi: 10.1038/nri978

37. Lu G, Zhang R, Geng S, et al. Myeloid cell-derived inducible nitric oxide synthase suppresses M1 macrophage polarization. Nat Commun. 2015;6:6676. doi: $10.1038 /$ ncomms7676

38. Blander JM, Medzhitov R. Regulation of phagosome maturation by signals from toll-like receptors. Science. 2004;304(5673):1014-1018. doi: 10.1126/ science.1096158

39. Doyle SE, O'Connell RM, Miranda GA, et al. Toll-like receptors induce a phagocytic gene program through p38. J Exp Med. 2004;199(1):81-90. doi: 10.1084/ jem.20031237

40. Watts C, West MA, Zaru R. TLR signalling regulated antigen presentation in dendritic cells. Curr Opin Immunol. 2010;22(1):124-130. doi: 10.1016/j. coi.2009.12.005 